\title{
Doença de Wilson e Gravidez. Relato de Caso
}

\author{
Pregnancy and Wilson's Disease. A Case Report
}

Ana Paula Brito Hortêncio, Carlos Augusto Alencar Júnior, José Milton de Castro Lima Daniela Maria Queiroz Medeiros Moreira, Joelma Oliveira Moreira

\begin{abstract}
RESUMO
A doença de Wilson (degeneração hepatolenticular) é distúrbio autossômico recessivo raro que usualmente ocorre entre a primeira e terceira décadas de vida. Caracteriza-se por depósito excessivo de cobre no figado e cérebro e é fatal se não diagnosticada e tratada precocemente. Os autores descrevem um caso de gravidez e doença de Wilson, mostrando a evolução satisfatória de uma paciente que fez uso da D-penicilamina até a sétima semana de gestação, quando a suspendeu por conta própria, e após a vigésima semana gestacional. A mãe evoluiu sem sinais de descompensação clínica ou obstétrica. O recém-nascido não apresentou nenhuma intercorrência e encontrava-se bem no final do primeiro ano de vida.
\end{abstract}

PALAVRAS-CHAVE: Doença de Wilson. Complicações da gravidez. Doença metabólica. Degeneração hepatolenticular.

\section{Introdução}

A doença de Wilson, também conhecida como degeneração hepatolenticular, é distúrbio genético do metabolismo do cobre, descrita como entidade clínica pela primeira vez por Wilson em $1912^{1}$. Entretanto, só em 1940 a doença foi relacionada ao acúmulo de cobre no figado e cérebro ${ }^{2}$.

Herdada em caráter autossômico recessivo, apresenta prevalência de 1 caso em cada 30.000 a 50.000 nascidos vivos. Sendo os pais homozigóticos, a chance de o filho nascer com a doença é de $25 \%$. O defeito genético encontra-se localizado no braço longo do cromossomo 13, na região 13q14. O produto do gene é uma ATPase transportadora do cobre, já tendo sido descritas várias mutações ${ }^{3}$.

Não obstante o metal seja, indubitavelmente, o responsável pela doença, não há correlação entre a concentração do cobre hepático e o tipo e gravidade da lesão do órgão. Jovens doentes assintomáticos podem ter niveis de cobre hepático muito superiores àqueles observados em pacien-

Hospital Universitário Walter Cantídio (HUWC) - Serviço de Gastroenterologia.

Maternidade Escola Assis Chateaubriand (MEAC) - Serviço de Medicina Materno-Fetal.

Universidade Federal do Ceará (UFC).

Correspondência:

Carlos Augusto Alencar Júnior

Rua Vicente Linhares, 1551/Apto. 1000 - Aldeota

60135-270 - Fortaleza - Ceará

Fone: (85) 258-3110/258-1383 Celular: 998-16112 tes em que a doença já progrediu para cirrose e acometimento do sistema nervoso central ${ }^{4}$.

A transição da forma assintomática para o grave comprometimento hepático ou cerebral varia, sendo que o diagnóstico só pode ser efetuado se anormalidades bioquímicas ou o aparecimento de sintomas levarem à investigação e descoberta dos achados patognomônicos ${ }^{4}$. Após mobilização do cobre do figado e sua deposição em outros órgãos, especialmente sistema nervoso central, córneas e rins, a síndrome completa poderá se desenvolver ${ }^{4}$.

Predomina em pessoas jovens, com 60 a $70 \%$ dos acometidos procurando cuidados médicos entre os 8 e 20 anos, sendo mais rara antes dos 3 e após os 40 anos $^{4}$. As manifestações clínicas são decorrentes do acúmulo de cobre nos diversos tecidos, principalmente figado, gânglios da base, córneas, rins e articulações ${ }^{2}$. Infelizmente, a maioria dos sintomas são inespecíficos, respondendo pela alta freqüência de diagnósticos efetuados tardiamente ou não-concretizados, especialmente em indivíduos sem história familiar. Muitos dos pacientes diagnosticados na forma assintomática apresentaram apenas uma transinemia inexplicada ou são irmãos ou parentes de pessoas com a doença clínica ${ }^{4}$.

O envolvimento hepático ocorre, em geral, antes dos 20 anos, ao passo que a forma neurológica tende a aparecer após os 20 anos, podendo existir superposição entre as duas formas da doença. As manifestações hepáticas podem se apre- 
sentar como hepatite crônica, cirrose e, mais raramente, hepatite fulminante. As alterações neurológicas são variáveis, predominando os sintomas extrapiramidais, tremores, distonia, disartria, alterações de humor, sintomas psiquiátricos e, se não tratada, diminuição progressiva da capacidade intelectual ${ }^{2}$.

É doença progressiva e fatal se não for diagnosticada e tratada precocemente. O diagnóstico baseia-se na presença do anel corneal de Kayser-Fleischer, na diminuição dos niveis séricos de ceruloplasmina (menor que $20 \mathrm{mg} / \mathrm{dL}$ em $96 \%$ dos pacientes) e aumento dos níveis plasmáticos e da eliminação urinária do cobre ${ }^{4}$. A biópsia hepática é essencial para o diagnóstico definitivo em pacientes assintomáticos ou com manifestações hepáticas. A concentração do cobre hepático superior a $250 \mathrm{mg} / \mathrm{g}$ permite o diagnóstico da doença se os achados histológicos são compativeis.

Desde que Walshe ${ }^{5}$, em 1956, introduziu a D-penicilamina no seu tratamento, as pacientes em uso contínuo apresentam bom prognóstico. Quando a função hepática é preservada a patologia não interfere na capacidade reprodutiva, sendo a capacidade procriativa normal. A gravidez, em geral, é bem tolerada.

Os autores descrevem um caso de doença de Wilson e gravidez, discutem as implicações da doença sobre a gravidez, as controvérsias do uso das medicações utilizadas no tratamento da patologia durante a gestação e lactação e os resultados materno e perinatal numa paciente acompanhada nos Serviços de Gastroenterologia do Hospital Universitário Walter Cantídio (HUWC-UFC) e de Medicina Materno-Fetal da Maternidade Escola Assis Chateaubriand da Universidade Federal do Ceará (SMMF-MEAC/UFC).

\section{Relato do Caso}

AMM, 17 anos, sexo feminino, estudante, branca, primigesta, casada, natural e procedente de Maranguape, Ceará. Aos onze anos, submeteuse a rastreamento para doença hepática hereditária, sendo firmado o diagnóstico de doença de Wilson. Na ocasião, encontrava-se assintomática, embora no exame físico evidenciasse eritema palmar, aranhas vasculares e hepatomegalia. A dosagem da ceruloplasmina foi de $6 \mathrm{mg} / \mathrm{dL}$ (normal: 20 a $60 \mathrm{mg} / \mathrm{dL}$ ). Submeteu-se à biópsia hepática, que revelou hepatite crônica fibrosante. $\mathrm{Na}$ história familiar, dois irmãos (13 e 15 anos) haviam falecido de doença hepática nos últimos 14 meses, antecedendo o seu diagnóstico. Os pais eram primos em primeiro grau. Os outros dois irmãos vivos não apresentavam alteração ao exame físico e a dosagem da ceruloplasmina era normal. Desde então, foi iniciado esquema com Dpenicilamina, na dose de 250 até $750 \mathrm{mg} /$ dia, tendo evoluído, desde então, de forma satisfatória, clínica e laboratorialmente. Encontrava-se aproximadamente na sétima semana gestacional quando, suspeitando estar grávida, suspendeu a medicação por conta própria. Reiniciou seu uso na vigésima semana gestacional, por orientação médica, com dose de $500 \mathrm{mg} /$ dia, sem qualquer sinal de descompensação clínica.

Ao iniciar o pré-natal, realizou a primeira ultra-sonografia obstétrica, que evidenciou ser a idade gestacional de 18 semanas, sem anormalidades. Havia erro de 4 semanas a menos em relação à data da última menstruação. Nas ecografias realizadas posteriormente, com 22 e 32 semanas, observaram-se condições placentárias, volume de líquido amniótico e crescimento e anatomia fetal aparentemente normais. O exame dopplervelocimétrico, realizado com 36 semanas, foi normal. Não foram dosados os niveis séricos de ceruloplasmina e os exames laboratoriais gerais não apresentaram alterações durante toda a gravidez.

Na quadragésima semana a paciente foi admitida em trabalho de parto, evoluindo sem complicações para parto vaginal. O recém-nascido, do sexo feminino, recebeu Apgar de $1^{\circ}$ minuto de 8 , pesou $3.310 \mathrm{~g}$, mediu $51 \mathrm{~cm}$ e teve Capurro somático estimado em 39 semanas, sendo considerado adequado para a idade gestacional. A puérpera e o recém-nascido receberam alta hospitalar, sem intercorrências, no segundo dia do pós-parto. A D-penicilamina foi substituída por sulfato de zinco (150 mg/dia). Após 1 ano de evolução, a mãe encontrava-se em bom estado e a criança sem qualquer alteração em seu crescimento e desenvolvimento.

\section{Discussão}

A gravidez em pacientes com doença de Wilson apresenta alguns dilemas que merecem ser discutidos e revisados para que possamos orientar melhor nossas pacientes.

Quando não há tratamento a gravidez é rara, sendo causa comum de amenorréia, infertilidade e abortos repetidos. Por outro lado, as pacientes com diagnóstico precoce e tratamento efetivo, preservando as funções hepáticas e neurológicas, apresentam uma vida saudável, podendo levar uma gravidez a termo sem maiores complicações ${ }^{5}$. 
A gestação também não interfere no curso natural da doença. Desta forma, pacientes bem tratadas, com evolução satisfatória, não têm impedimento específico para engravidarem ${ }^{5}$.

Um outro aspecto refere-se ao uso das drogas disponiveis na terapia da doença de Wilson durante a gravidez. No arsenal terapêutico temos os agentes quelantes do cobre, representados pela D-penicilamina e trientina, que aumentam a excreção urinária do cobre; e os agentes que agem inibindo a absorção do cobre em nível intestinal, sendo os mais utilizados o acetato e o sulfato de zinco $^{6}$. Embora vários trabalhos relatem a segurança dessas drogas durante a gravidez, existem controvérsias. Mesmo assim, é importante a manutenção da terapia quelante ou com o acetato ou sulfato de zinco, tendo em vista que a suspensão da medicação está associada a maior número de partos prematuros e risco de complicação da doença hepática e neurológica ${ }^{5}$.

A experiência maior é com a Dpenicilamina. Briggs et al. ${ }^{7}$ classificam esta droga na classe de risco $\mathrm{D}$, ou seja, que há evidência positiva de risco para o feto, mas que seu uso durante a gravidez pode ser aceito para aquelas pacientes em que a doença seja fatal, se não tratada, como é o caso da doença de Wilson. Na gravidez, quando indicada para o tratamento da artrite reumatóide, o fármaco deve ser suspenso ${ }^{8,9}$.

Existem descritos mais de 100 casos nos quais se empregou a medicação durante a gestação. A maioria dos recém-nascidos foram saudáveis, com bom desenvolvimento físico e intelectual. Algumas anormalidades têm sido referidas em pequeno número de casos: cútis laxa, hérnias inguinais, hiperflexão de articulações, provavelmente associadas com o efeito da droga no tecido conjuntivo ${ }^{7}$.

Para as pacientes que serão submetidas à cesárea, orienta-se utilizar dose menor da Dpenicilamina, 250 a $500 \mathrm{mg}$, quando a dose usual é de 750 a $1.500 \mathrm{mg} /$ dia, visto que a droga altera a formação do colágeno, dificultando a cicatrização da ferida cirúrgica ${ }^{7}$. Embora seja possivel, não há relatos evidenciando diminuição da cicatrização nessas pacientes.

A trientina é classificado como risco $\mathrm{C}$ e seria uma opção nos casos com envolvimento neurológico agudo e, principalmente, quando há intolerância à D-penicilamina. Apresenta menos efeitos colaterais, porém não se encontra disponivel no Brasil. Embora pareça segura na gestação, os relatos de seu uso são escassos ${ }^{7}$.

Walshe ${ }^{5}$ descreveu 7 casos de pacientes com doença de Wilson tratadas com trientina, considerando-a droga segura, apesar de ter sido descrito um caso de criança com isocromossomo X. Seu uso, no momento, parece não ser aconselhável durante a gestação, já que existem drogas menos tóxicas, como o próprio sulfato de zinco.

$\mathrm{O}$ acetato de zinco foi liberado pelo FDA, em 1997, para o tratamento da doença de Wilson, inclusive durante a gravidez, demonstrando ser seguro e com poucos efeitos colaterais, sendo classificado como risco $\mathrm{A}^{6}$. Porém, há poucos relatos utilizando o sulfato ou acetato de zinco nessas pacientes. É possivel que se torne a droga de escolha para tratamento das gestantes com doença de Wilson, na dose de $50 \mathrm{mg}$ de acetato de zinco ou $250 \mathrm{mg}$ de sulfato de zinco, três vezes ao dia ${ }^{6}$.

No presente caso, apesar da suspensão do tratamento entre a $7^{\mathrm{a}}$ e $20^{\mathrm{a}}$ semanas, a paciente evoluiu bem, sem apresentar intercorrências. Não houve repercussões cicatriciais na episiorrafia.

Nenhuma das alterações fetais descritas na literatura, supostamente provocadas pela utilização da D-penicilamina, foi observada. O recémnascido não teve malformações diagnosticadas ao nascimento, recebeu alta sem complicações e continuava bem no final do primeiro ano de vida.

\section{SUMMARY}

Wilson's disease (hepatolenticular degeneration) is a rare autosomal recessive disorder that usually occurs between the first and third decades. The condition is characterized by excessive deposition of copper in the liver and brain. It is fatal if the diagnosis and treatment are not performed early in life. The authors describe one case of pregnancy and Wilson's disease, showing the good evolution of the patient, who used D-penicillamine until the seventh week of gestation, discontinuing thereafter until the 20th week of gestation. The mother evolved with no signs of clinic and obstetric problems. The newborn did not present any problem and was healthy in his first year of life.

KEY WORDS: Wilson's disease. Pregnancy complications. Metabolic disease. Hepatolenticular degeneration.

\section{Referências}

1. Wilson SAK. Progressive lenticular degeneration: a familial nervous disease associated with cirrhosis of the liver. Brain 1912; 34:295.

2. Saas-Kostsak A, Bearn AG. Wilson's disease. In: Stanbury JB, Wyngaarden JB, Fredickson DS, editors. The Metabolic Basis of Inherited Disease. $4^{\text {th }}$ ed. New York: McGraw-Hill; 1978. p.1098. 
3. Tanzi RE, Petrukhin K, Chernov I, et al. The Wilson's disease gene is a copper transporting ATPase with homology to the Menkes disease gene. Nat Genet 1993; 5:344-50.

4. Sternlieb I. Wilson's disease. Clin Liver Dis 2000; 4:229-39.

5. Walshe JM. Pregnancy in Wilson's disease. Q J Med 1977; 46:73-83.

6. Anderson LA, Hakojarvi SL, Boudreaux SK. Zinc acetate treatment in Wilson's disease. Ann
Pharmacother 1998; 32:78-87.

7. Briggs GG, Freeman RK, Yaffe SJ. Drugs in pregnancy and lactation. 5th ed. Baltimore: Williams \& Wilkins; 1998. p.824-6.

8. Little BB. Immunosuppressant therapy during gestation. Semin Perinatol 1997; 21:143-8.

9. Ostensen M, Ramsey-Goldman R. Treatment of inflammatory rheumatic disorders in pregnancy: what are the safest treatment options? Drug Saf 1998; 19:389-410.

\title{
XIVCONGRESSOBAIANO DEGINEOOLOGIAE OBSTETRÍCA
}

\section{3 a 15 de Setembro de 2001}

\author{
Salvador-BA
}

Organização: SOGIBA

Tel.: (0xx71) 351-5907 